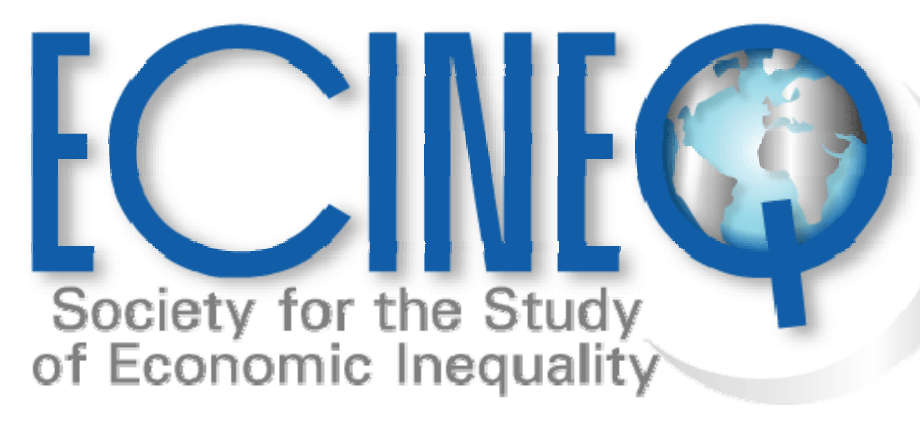

Working Paper Series

Technological Change, Inequality and Work Sharing

Thomas Moutos

ECINEQ WP 2006 - 30 


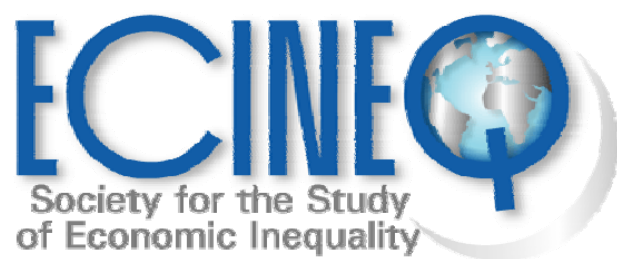

ECINEQ 2006-30

March 2006

www.ecineq.org

\title{
Technological Change, Inequality and Work Sharing*
}

\author{
Thomas Moutos ${ }^{\dagger}$ \\ AUEB and CESifo
}

\begin{abstract}
The effects of technological change on wage inequality are usually studied under the assumption of exogenous supplies of skilled and unskilled workers. Moreover, in these studies there is no distinction between the stock (number of workers) and the flow (hours of work) dimension of labour services. In the present paper we construct a model in which hours of work and technological change affect both the (relative) demand and supply of unskilled workers. The labour supply of unskilled workers (numbers of persons) is derived from a model of household labour supply in which households differ regarding the disutility suffered when both household members work. Combining together the (relative) supply and demand parts of the model we are able to study the effects of technological change on wage and income inequality and to provide an explanation of recent trends more consistent with the stylized facts.
\end{abstract}

Keywords: technological change, inequality, household labour supply, work sharing JEL Classification: D33, E25, J22, J31.

\footnotetext{
*I wish to thank Jonas Agell, Spyros Vassilakis, Vanghelis Vassilatos for helpful comments and suggestions. The advice and comments of two anonymous referees and the editor (Campbell Leith) have improved both the substance and presentation of the paper.

${ }^{\dagger}$ Contact details: DIEES, AUEB, Patission 76, Athens 104 34, Greece. Email: mkatsimi@aueb.gr, tmoutos@aueb.gr
} 


\section{Introduction}

One of the well-known facts of the last two decades has been the deterioration of the economic position of less-skilled workers in some OECD countries. In the United States, for example, the ratio of earnings of the 90th percentile of the wage distribution to the 10th percentile increased sharply from 2.66 to 3.66 between 1971 and 1995 (see, Freeman (1995)). Almost all of the research effort during the last decade has assumed that the rise in the relative wage of college-educated workers (the so-called "skill-premium") has been due to a rise the (relative) demand for skilled (i.e. college-educated) workers and has tried to uncover the factors responsible for this shift in the (relative) demand for skilled labour. ${ }^{1}$ The initial response of some authors was to link this development to increased trade exposure with low-wage countries, both as a source of imports and as hosts for foreign investors. This explanation has been mostly discredited as it has been pointed out that trade between the North and the South is still too small to have had a significant effect on Northern labour markets (for an opposite view, see Wood (1994)). The favoured explanation among empirical researchers regarding the causes of these changes is skill-biased technological change (SBTC) which has improved the wage and employment prospects of relatively skilled workers, while simultaneously damaging the wage and employment prospects of less skilled workers (see, for example, Juhn et al (1993), Berman et al (1997), and Machin and Van Reenen (1998)).

The standard theoretical framework for examining the effects of technological change on the skill premium implies that in order for SBTC to be able to explain the recent rise in inequality, the elasticity of substitution between skilled and unskilled workers must be greater than 1(e.g., Acemoglu (2002)). However, the empirical evidence about the elasticity of substitution between skilled and unskilled workers provides little support for this assumption. Despite the inherent difficulties in estimating this elasticity of substitution (since the data involve substitution both within and across industries), the evidence suggests that, more likely than not, it is less than 1 (see, for example, the extensive review of the literature in Hammermesh (1993)). It would thus appear that SBTC is an unlikely explanation of the rise in the skill premium.

\footnotetext{
${ }^{1}$ Gordon (1995) has argued that the rise in inequality may be due to the fact that US firms have decided that it is more profitable for them to use overbloated bureaucracies (instead of high wages) in
} 
Nevertheless, in the present paper we show that once we allow for technological change to impact not only on the relative demand for (un)skilled workers, but on their relative supply as well, the hypothesis of SBTC can explain the rise in inequality even when the elasticity of substitution between skilled and unskilled workers is less than 1. This is potentially important since failure to establish technological change as a main cause of the rise in inequality may imply that either trade liberalization and/or domestic policy changes were the driving forces, thus potentially creating the political climate for inappropriate policy responses (e.g. anti-globalization movement, etc.).

A common feature of the papers dealing with the effects of technological change is their exclusive focus on the relative demand for (un)skilled workers: whereas relative labour demand is assumed to respond directly to technological change, the relative supply of (un)skilled workers is assumed constant ${ }^{2}$. In this paper we first construct a general equilibrium model in which technological change, impacts not only on the relative demand of (un)skilled workers but on the relative supply as well. This is accomplished by explicit modelling of the labour force participation decision in households comprised of two potential participants in the labour market. We assume that households differ not only with respect to the composition of skills each household member is endowed with, but also with respect to the disutility suffered when both household members are participating in the labour force. Thus we are able to derive the aggregate relative supply of unskilled workers as a positive function of the real (hourly) unskilled wage and a negative function of (the exogenously given) hours of work. As we explain in the following section, the evidence presented in Blundell and McCurdy (1999) and Blau and Kahn (2005) lends support to the empirical relevance of this function.

The implications which follow from having the aggregate supply of unskilled workers being -ceteris paribus- a positive function of the real wage, are as follows. First, skillbiased technological progress can result in an increase in wage inequality (i.e., the skill premium) even if the elasticity of substitution between skilled and unskilled

order to "discipline" their workers.

${ }^{2}$ An exception is the work of Gregg and Manning (1996) who postulate that labour supply is a function of the relative wage rate between skilled and unskilled workers. In addition, many authors have examined empirically the impact of changes in labour supply on the cross-country patterns of inequality (e.g. Card et al (1999), Murphy et al (1998)). 
workers is less than 1. Second, we show that neutral technological progress can increase the skill premium, independently of the value of the elasticity of substitution. ${ }^{3}$ Both of these findings follow as a consequence of the increase in the relative supply of unskilled workers, which results from the positive impact of technological progress on the real wages of the unskilled. Third, changes in the (sometimes institutionally set) working time of unskilled workers can impact on the skill premium, thus providing another (partial) explanation for the diverging trends in inequality between the United States and the United Kingdom on one hand and continental European countries on the other (see, Freeman and Katz (1995), and Gottschalk and Smeeding (1999) for the relevant evidence).

In the remainder of the paper, we first present the model (section 2), and then proceed to analyze the effects of neutral and biased technological change, as well as the effects of changes in hours of work on the skill premium and the real wages of the unskilled (section 3). Section 4 concludes the paper and offers some caveats of our analysis.

\section{The Model}

We describe a perfectly competitive economy, producing a single good (Q) with the use of skilled (S) and unskilled (L) labour.

\subsection{Firms}

The production function is assumed to take the CES form

$$
Q=A \cdot\left\{\left(A_{L} L\right)^{\rho}+\left(A_{S} S\right)^{\rho}\right\}^{1 / \rho}
$$

where $A$ is a constant reflecting the state of technology, $A_{L}$ and $A_{S}$ are factor augmenting technology terms, and $\rho \leq 1$. The elasticity of substitution between skilled and unskilled workers in this production function is $\sigma \equiv 1 /(1-\rho)$. The value of the elasticity of substitution is of crucial importance in this framework since, depending on it, an increase in, for example, $A_{S}$ can be considered as a force

\footnotetext{
${ }^{3}$ For a demonstration of the same phenomenon in the context of a two-sector general equilibrium model with vertically-differentiated products, see Moutos (2000).
} 
"complementing" or "replacing" skilled workers.

In equation (1), $S$ measures the number of skilled workers, whereas $L=f(h, N)$, with $h$ being the (legislated) hours per worker per period and $N$ the number of unskilled workers. In other words, we assume that the labour services of skilled workers are defined only by the number of them, whereas the labour services of unskilled workers are a function of the number of unskilled workers and hours per worker. This distinction between skilled and unskilled workers is made in order to capture the fact that skilled workers are involved in more than "turn-key" procedures, and that their contribution to production is to some extent independent of the number of hours spent at the factory. In any case, the prevalence of salaries (rather than wages) as the mode of compensation among skilled workers testifies to the (relative) unimportance of conventionally set hours of work as a determinant of labour services for skilled workers. Moreover, as Coleman and Pencavel (1993) and Costa (1998) have documented for the United States, since 1940 there have been ongoing decreases in the (weekly) hours of work for those with a high school education or less, and increases in the hours of work for the college educated. Thus, it appears that the legislated hours of work set a standard only for the less-skilled workers. It is also worth noting that the qualitative nature of our results would remain largely intact had we assumed that average hours of work influence the amount of labour services performed by skilled workers, as long as it does so at a lesser extent than for unskilled workers.

The specification of the labour services function is a crucial issue in models examining the impact of changes in hours of work on labour demand under the assumption of perfectly elastic labour supply (see, for example, Hart (1987) and Hart and Moutos (1995)). In the present context it is less important since employment is determined jointly with an upward sloping labour supply curve (see the following subsection). For this reason, and in order to keep the model tractable, we adopt the following simple specification of the labour services function,

$L=h N \quad$. 
This specification implies that (unskilled) labour productivity is not affected by changes in the hours of work. There exist strong arguments that lend support to the possibility of either a rise or a fall in labour productivity following a reduction in hours of work. For example, a reduction in hours of work may help to increase (hourly) productivity due to a reduction in fatigue and boredom. On the opposite side, suppose that a significant part of a firm's effective man-hours are devoted to machine set-up time. A fall in hours of work may, in this case, cause a reduction in productivity since proportionally less time is devoted to direct production activity. Unfortunately, the empirical evidence has been less than clear-cut in this respect (see, Hart (1987)). For this reason, no attempt is made to integrate the (uncertain) productivity effects of changes in hours of work in this paper.

The cost-minimizing demands for factor services corresponding to production function (1) are,

$$
\begin{aligned}
& L_{D}=h N_{D}=Q A^{-1} w^{1 /(\rho-1)} A_{L}^{-\rho /(\rho-1)}\left[w^{\rho(\rho-1)} A_{L}^{-\rho /(\rho-1)}+r^{\rho /(\rho-1)} A_{S}^{-\rho /(\rho-1)}\right]^{-1 / \rho} \\
& S_{D}=Q A^{-1} r^{1 /(\rho-1)} A_{S}^{-\rho /(\rho-1)}\left[w^{\rho /(\rho-1)} A_{L}^{-\rho /(\rho-1)}+r^{\rho(\rho-1)} A_{S}^{-\rho(\rho-1)}\right]^{-1 / \rho}
\end{aligned}
$$

where $L_{D}$ and $S_{D}$ stand for the demand of unskilled and skilled labour services (respectively), $w$ is the hourly wage rate of unskilled workers and $r$ is the wage rate of skilled workers. The resulting average cost, $A C$, (and thus, price $P$ ) function is

$$
P=A C=A^{-1}\left[w^{\rho /(\rho-1)} A_{L}^{-\rho /(\rho-1)}+r^{\rho /(\rho-1)} A_{S}^{-\rho /(\rho-1)}\right]^{(\rho-1) / \rho} .
$$

We note that the average cost is not directly dependent on hours of work, an implication of our assumption that productivity is hours independent. However, to the extent that factor prices may depend on hours worked, average costs (and thus prices) may be not be hours independent once the general equilibrium repercussions are taken into account.

\footnotetext{
${ }^{4}$ A related issue concerns the use of overtime hours. Firms using overtime may respond to a cut in standard hours of work by increasing overtime, since it results in a rise in the marginal cost of an additional worker relative to the marginal cost of overtime (for more details, see Hart (2004)). For simplicity, and with some loss of generality, we assume that hours worked are equal to (legislated) standard hours.
} 


\section{2 Households}

Households consist of two potential participants in the labour market. There are three possible groups of households, depending on the type of household members: $(\mathrm{S}, \mathrm{S})$, $(\mathrm{S}, \mathrm{L})$, and $(\mathrm{L}, \mathrm{L})$. We assume that all skilled individuals participate in the labour market and, since the labour market clears, that all skilled individuals work. This assumption is made in order to capture both the idea that skill acquisition is a purposeful activity, and the fact that the proportion of labour market participation among skilled workers is significantly higher than for the unskilled for both men and women (see, Blundell and McCurdy (1999)). ${ }^{5}$ It is worth noting that our results do not hinge on assuming that all skilled individuals participate in the labour force. Indeed, as long as the own wage elasticity of labour supply of skilled individuals is smaller than the corresponding wage elasticity of unskilled individuals, then the qualitative nature of our results would remain intact. The existing econometric evidence provides clear support for this hypothesis, and more so for female workers who are usually the secondary household earner (see, Blundell and McCurdy (1999) and Blau and Kahn (2005)). We also assume that in every household, at least one of its members is willing to work, and thus is employed. Consequently, for household groups $(\mathrm{S}, \mathrm{L})$ and $(\mathrm{L}, \mathrm{L})$, it is possible to have the second household member either being a member of the labour force (and thus working) or not. Thus, taking into account labour market participation the possible household groups are: $(\mathrm{S}, \mathrm{S}),(\mathrm{S}$, $\left.\mathrm{L}_{P}\right),\left(\mathrm{S}, \mathrm{L}_{N P}\right),\left(\mathrm{L}, \mathrm{L}_{P}\right),\left(\mathrm{L}, \mathrm{L}_{N P}\right)$, with the subscripts $\mathrm{P}$ and NP standing for participation and non-participation, respectively. Accordingly, there are five groups in the economy, with the following incomes (respectively): $2 \mathrm{r}, \mathrm{r}+\mathrm{w}, \mathrm{r}, 2 \mathrm{w}, \mathrm{w}$.

We assume that households differ in only one aspect regarding their preferences, namely the disutility experienced when the second household member works. Utility depends on consumption, $\mathrm{C}$ and on leisure (or, alternatively, on the amount of home production which leisure can produce),

$U_{i}=C_{i}-h-a h^{\pi_{i}}, \quad \pi_{i}>1$

\footnotetext{
${ }^{5}$ An interesting extension of the present paper may involve the modeling of the proccess by which individuals decide to acquire skills.
} 
with $\pi_{i}$ being a parameter which varies across households, and $a=1(=0)$ when the second household member works (does not work), respectively. Households maximize utility subject to the budget constraint

$P C_{i}=y_{1, i}+a y_{2, i}$,

with $y=r$ for skilled workers, and $y=w h$ for unskilled workers. It is worth noting that since all skilled individuals work, $y_{2}=w h$ for household groups $(\mathrm{S}, \mathrm{L})$ and $(\mathrm{L}$, L). A household belonging to these two groups will have both of its members working if $U_{a=1}>U_{a=0}$. Thus, for the marginal household (which is indifferent between sending its second member to work and enjoying the extra consumption of marketproduced goods, and the home production (or leisure) which having the second member at home implies), it holds that

$w h / P=h^{\pi_{m}}$,

with the subscript $m$ denoting the marginal household. Let $E$ denote the real hourly wage $(=w / p)$ for unskilled workers. Then, $E h=h^{\pi_{m}}$, which implies that

$\pi_{m}=1+(\ln E / \ln h)$.

We now assume that $\pi$ is uniformly distributed in the interval $\left(1, z_{1}\right]$ among households in the group $(\mathrm{S}, \mathrm{L})$, and in the interval $\left(1, z_{2}\right]$ among the $(\mathrm{L}, \mathrm{L})$ households ${ }^{6}$. Let $K_{1}$ and $K_{2}$ be the numbers of households belonging to the two groups. Then,

$\pi_{i}=1+\left(\left(z_{1}-1\right) / K_{1}\right) \cdot i, \quad i=1, . . i_{m} . ., K_{1}$

\footnotetext{
${ }^{6}$ It may be reasonable to assume that the value attached to leisure by an unskilled worker who lives with a skilled worker is likely to be higher than one who lives with an unskilled worker, because consumption is, to some extent at least, spread within the household. The results of our analysis do not in any way depend on abstracting from this issue.
} 
$\pi_{j}=1+\left(\left(z_{2}-1\right) / K_{2}\right) \cdot j, \quad j=1, . . j_{m} . ., K_{2}$.

Let $i_{m}$ and $j_{m}$ stand for the marginal household in the two groups. Accordingly,

$\pi_{m, i}=1+\left(\left(z_{1}-1\right) / K_{1}\right) \cdot i_{m}$

$\pi_{m, j}=1+\left(\left(z_{2}-1\right) / K_{2}\right) \cdot j_{m}$

and the marginal households are defined as

$i_{m}=\left(\left(\pi_{m, i}-1\right) /\left(z_{1}-1\right)\right) K_{1}$

$j_{m}=\left(\left(\pi_{m, j}-1\right) /\left(z_{2}-1\right)\right) K_{2}$.

The aggregate supply (number of persons) of unskilled workers is

$$
L_{S}=\int_{0}^{i_{m}} 1 d i+\int_{0}^{j_{m}} 2 d j+\int_{j_{m}}^{K_{2}} 1 d j
$$

The first term (of the right-hand-side of equation (9)) counts those (S, L) households for which $\pi_{i}<\pi_{m, i}$, thus those having the second (unskilled) member offering her/his labour services to the market. The second term counts those $(\mathrm{L}, \mathrm{L})$ households for which $\pi_{j}<\pi_{m, j}$, thus those having both (unskilled) members participating. The third term counts the rest of the (L, L) households (those with $\pi_{j}>\pi_{m, j}$ ) for which only the first member is working. Using equations (7) and (8) we calculate the aggregate supply of unskilled workers to be

$$
L_{S}=K_{2}\left(1+\frac{\ln E}{\left(z_{2}-1\right) \ln h}\right)+K_{1}\left(\frac{\ln E}{\left(z_{1}-1\right) \ln h}\right)
$$

We note that the labour supply (number of persons) of unskilled workers is increasing in the real hourly wage $(E)$ and decreasing in the hours of work $(h)$. In what follows 
we will assume that although changes in the hours of work induce changes in the number of unskilled workers in the opposite direction, the supply of unskilled labour services changes in the same direction.

\section{Analysis}

Let $K_{3}$ denote the number of $(\mathrm{S}, \mathrm{S})$ households. Then, the aggregate supply of skilled workers (and skilled labour services) is $2 K_{3}+K_{1}$. Although equation (10) defines the labour supply of unskilled workers the aggregate supply of unskilled labour services is equal to $h L_{S}$. Equating the relative supply of unskilled labour services to the relative demand for these services (as is determined from equations (3) and (4)) we get,

$h\left[K_{2}\left(1+\frac{\ln E}{\left(z_{2}-1\right) \ln h}\right)+K_{1}\left(\frac{\ln E}{\left(z_{1}-1\right) \ln h}\right)\right] /\left(2 K_{3}+K_{1}\right)=\left[\frac{w}{r}\left(\frac{A_{S}}{A_{L}}\right)^{\rho}\right]^{1 /(\rho-1)}$.

Looking at equation (11), we note the presence of the factor-augmenting technology terms $\left(A_{S}\right.$ and $\left.A_{L}\right)$, and the absence of the term capturing the general state of technology $(A)$. However, this does not imply, as we will presently see, that neutral technological change has no impact on relative wages (the so-called skill premium). We normalise by setting $w=1$. Equation (11) along with the definition of $E(=w / p)$ and the price level -determining equation (5), solve for the (relative) wage of the unskilled $r$ and the real (hourly) wage $E$ (which is the inverse of the price level) of unskilled workers. Following the literature, we will refer to $r$ as the skill premium.

\subsection{Skill-Biased Technological Change}

In models in which the relative supply of (un)skilled workers is constant, the effects of biased (factor-augmenting) technological change depend on the elasticity of substitution $\sigma(=1 /(1-\rho))$ between skilled and unskilled workers ( Acemoglu (2002)). If $\sigma>1$ ( in which case, $\rho \in(0,1])$, then an increase in the (relative) productivity of skilled workers $\left(A_{S}\right)$, will increase the skill premium. Conversely, if 
$\sigma<1(=1)$, then an increase in $A_{S}$ will decrease (not change) the skill premium ${ }^{7}$.

Given that the conventional wisdom is that the recent rise in the skill premium is due to SBTC, this framework is consistent with the facts, if, and only if, $\sigma>1$. However, the empirical evidence about the elasticity of substitution is less than clear-cut on this issue. In fact, the evidence (see, for example, Eisner and Nadiri (1968), Lucas (1969) and the extensive review of the literature in Hammermesh (1993)) suggests that, more likely than not, it is less than unity.

In the present paper, the effects of changes in $A_{S}$ and $A_{L}$ are,

$$
\begin{aligned}
& d r / d A_{S}=\left\{h \psi \mu^{-1} r^{\rho /(\rho-1)} A_{S}^{(1-2 \rho) /(\rho-1)} E^{-1}(\ln h)^{-1}-\rho J r^{1 /(1-\rho)}\left(A_{S} / A_{L}\right)^{1 /(\rho-1)} /(\rho-1) A_{L}\right\} / \Delta \\
& d E / d A_{S}=J \mu^{-1}\left\{\rho A_{L}^{(1-2 \rho) /(\rho-1)}-A_{S}^{-1} A_{L}^{\rho /(1-\rho)}\right\} /(\rho-1) \Delta
\end{aligned}
$$

where,

$$
\begin{aligned}
& \psi \equiv K_{1} /\left(z_{1}-1\right)+K_{2} /\left(z_{2}-1\right)>0 \\
& \Delta \equiv h \psi E^{-1} \mu^{-1}(\ln h)^{-1} r^{1 /(\rho-1)} A_{S}^{-\rho /(\rho-1)}+J E^{-1} r^{-\rho /(\rho-1)}\left(A_{S} / A_{L}\right)^{\rho /(\rho-1)} /(1-\rho)>0 \\
& J \equiv 2 K_{3}+K_{1}>0 \\
& \mu \equiv A_{L}^{-\rho /(\rho-1)}+r^{\rho /(\rho-1)} A_{S}^{-\rho /(\rho-1)}>0 .
\end{aligned}
$$

From equation (12) we observe that even if $\rho \leq 0(\sigma \leq 1)$, it is still possible for skillbiased technological change (i.e., a rise in $A_{S}$ ) to result in an increase in the skill premium. This occurs because the technological improvement can lead to a rise in the real wage of unskilled workers, thus inducing an increase in the relative supply of unskilled workers. We indeed note from equation (13) that when the elasticity of substitution between skilled and unskilled workers is less than (or equal to) one $(\rho \leq 0)$, then the real wage of unskilled workers increases in response to SBTC. We thus conclude that in our framework, SBTC can explain the rise in the skill premium

\footnotetext{
${ }^{7}$ A way to understand the difference in results caused by a low elasticity of substitution is to consider the extreme case of a Leontief production function $(\sigma=0)$. In that case, an increase in $A_{S}$ is equivalent to creating an "excess supply" of skilled workers since the number of unskilled workers is given, and it results in a decrease in the relative wage of skilled workers.
} 
for empirically relevant values of the elasticity of substitution between skilled and unskilled workers.

Nevertheless, as both both Gordon (2002) and Card and DiNardo(2002) have argued, the hypothesis of SBTC faces some problems in accounting for some of the shifts in the structure of wages that have occurred in the United States. A fundamental problem for the SBTC hypothesis is that wage inequality stabilized before 1990, despite continuing advances in information technology. The hypothesis of SBTC also does not explain why most of the rise in hourly wage-inequality occurred by 1984, the year that the IBM-AT was introduced. It also fails to explain the fall during the 1980s of the wage of college graduates with the strongest computer skills (e.g. computer science and electrical engineering) relative to the wage of social science graduates, despite a rise in the relative supply of social science graduates (see, OECD (2002)). These observations notwithstanding, there exists some doubt about whether the information revolution of the last 20 years can indeed be classified as SBTC, in the sense of augmenting the productivity of skilled (i.e., college educated) workers relative to the productivity of unskilled workers. It is usually alleged that in many countries (the US being the prime example) there is an undergoing transformation into a knowledge-age, computer-driven economy, one in which there is increasing emphasis on the command of knowledge, information, and the ability to harness the power of micro-processors. This transformation, is alleged, generates a technologydriven increased demand for individuals whose education and skills are able to exploit the new technologies.

Some authors (e.g., Gordon (2002)) have expressed doubts about the likelihood of SBTC as conventionally portrayed. Their doubts are also strengthened by the following two pieces of evidence from the United States. First, Hecker (1992) found that the proportion of college graduates aged 25 and older in what he termed "noncollege jobs" increased from $11 \%$ in 1970 to $20 \%$ in 1990 . Hecker addressed the apparent paradox that both college premiums and the proportion of college graduates in non-college jobs increased during this period. He considered and rejected the argument that large numbers of graduates were of low ability and did not qualify for "college-level" jobs. Instead, he argued that there continued to be an oversupply of college graduates relative to the number of college jobs. College graduates were 
therefore displacing high school graduates in non-college jobs. As a result, the college premium was increasing not because there was an increase in the relative demand for college graduates, but because high school graduates were earning less. Second, McCormick et al. (1996) reported that the proportion of new college graduates reporting that their job did not require college-level skills increased continuously from $24 \%$ in 1976 to $44 \%$ in 1994. The largest part of the increase (13 of 20 percentage points) occurred between 1976 and 1985. Again, this set of observations can hardly be reconciled with the view that SBTC was increasing the need for workers with college level skills, i.e. workers able to harness and exploit the new technologies.

The above arguments notwithstanding, allowing for recent technological changes to impact more on the productivity of unskilled workers (those with a high-school degree or less) than on the productivity of skilled workers is by no means far fetched. For example, most people would agree that the recent advances in word processing have increased the productivity of a professor less than her secretary. By the same token, the productivity of car park attendants, bank tellers and supermarket cashiers has increased considerably more due to recent electronic advances than, for example, the productivity of marketing executives. Equations (14) and (15) portray the effects of unskill-biased technological progress on the skill premium and the real wages of the unskilled:

$d r / d A_{L}=\left\{h \psi \mu^{-1} A_{L}^{(1-2 \rho) /(\rho-1)}(E \ln h)^{-1}+\rho J r^{1 /(1-\rho)}\left(A_{S} / A_{L}\right)^{1 /(\rho-1)} A_{S} E^{-1} /(\rho-1) A_{L}^{2}\right\} / \Delta$

$d E / d A_{L}=-J \mu^{-1}\left\{\rho A_{L}^{(2 \rho-1) /(1-\rho)}+r^{\rho /(1-\rho)} A_{S}{ }^{\rho /(\rho-1)} A_{L}^{(1-2 \rho) /(\rho-1)}\right\} /(\rho-1) \Delta$

As equations (14) and (15) reveal, a rise in $A_{L}$ can lead both to a rise in the skill premium and to a fall in the real wage of the unskilled, if the elasticity of substitution is less than one. The latter result is also consistent with the decline of the real wages of unskilled workers in the United States since the early seventies (see, Freeman (1995)).

\subsection{Neutral Technological Change}

An increase in parameter $A$ is a case of neutral technological progress. In models in which the relative supply of (un)skilled workers is constant, a change in $A$ has no effect on the skill premium. We find, instead, that (after setting the initial value of $A$ 
equal to one) the effects on the skill premium, $r$, and on the real wage of the unskilled, $E$, are

$d r / d A=h \psi / E \Delta \ln h>0$,

$d E / d A=-\left(2 K_{3}+1\right) r^{-\rho /(\rho-1)}\left(A_{S} / A_{L}\right)^{\rho /(\rho-1)} /(\rho-1) \Delta>0$

We thus find that, following a neutral technological progress there will be a rise in the skill premium and a rise in the real wage of the unskilled. The rise in the skill premium is a consequence of the increase in the (relative) supply of unskilled labour which the rise in real wages, as a result of the increase in $A$, brings about. It is thus possible, in principle, to explain the rise in the skill premium without having to rely on the assumption of biased (skilled or otherwise) technological change.

\subsection{Hours of Work}

Most economists would agree that Europe and the United States have experienced similar technological developments during the last three decades. Nevertheless, there have been significant differences in inequality patterns across the Atlantic. Wage inequality in, for example, France and Germany, has not increased during the same period; in fact it has decreased (Freeman and Katz (1995), Machin and van Reenen (1998)). The standard explanation for this divergent behaviour is institutional. For example, Krugman (1995) argued that (continental) European labour market institutions encourage wage compression, thus limiting the extent of inequality increases. The flip side of this argument is that in European countries, the unemployment rates of unskilled workers should rise relative to the unemployment rates of skilled workers. However, in the European countries, the unemployment rates for unskilled workers did not rise faster than the unemployment rates for skilled workers (Nickell and Bell (1996)), and unskilled employment did not grow faster in the United States than in the European economies (Card et al (1999)).

In addition to technological progress, many countries have also experienced continuous and significant reductions in working time. These reductions have taken 
many forms, including shorter working days, shorter working weeks, shorter working lives, and longer vacations. Maddison (1991), estimates that for the OECD countries the number of hours worked per-capita in one year has fallen by about $37 \%$ during the period 1870-1970. As Table 1 reveals this reduction in working time continued from the 1970 s to the present day for some OECD countries, with the United States and the United Kingdom providing a significant exception to this trend. We will argue that this reversal of the trend for the United States and the United Kingdom may also be an important factor explaining the recent rise in pay inequality in these countries (and the absence of a similar rise in the continental European countries).

Table 1: Percentage Changes, 1976-1996

\begin{tabular}{|l|c|l|l|l|l|}
\hline & Germany* & France & UK & Japan & US \\
\hline Population & 2.1 & 10.3 & 5.2 & 10.8 & 21.8 \\
\hline Total Employment & 4.9 & 3.6 & 5.5 & 22.4 & 42.8 \\
\hline $\begin{array}{l}\text { Manufacturing Sector } \\
\text { Employment }\end{array}$ & -3.1 & -29.5 & -22.2 & 7.4 & -2.8 \\
\hline $\begin{array}{l}\text { Working Time per } \\
\text { Employee (Manufact.) }\end{array}$ & -8.9 & -9.3 & 0.5 & -5.0 & 3.7 \\
\hline
\end{tabular}

* The time interval for Germany is 1973-1990.

Sources: ILO Labour Statistics Database, OECD Annual Hours Database.

We now argue that differential developments in the hours of work across the Atlantic may provide a partial explanation for the cross-country differences in inequality developments since the mid-seventies. We find that,

$d r / d h=\left\{(\psi \ln E / \ln h)\left(1-(\ln h)^{-1}\right)+K_{2}\right\} / E \Delta>0$

$d E / d h=-\left\{(\psi \ln E / \ln h)\left(1-(\ln h)^{-1}\right)+K_{2}\right\} A_{S}{ }^{\rho /(1-\rho)} r^{1 /(\rho-1)} / \mu \Delta<0$.

The skill premium rises in response to a rise in the hours of work since the latter change brings about an increase in the relative supply of unskilled labour services. The real (hourly) wage rate of the unskilled declines as a consequence, since the change in the hours of work is assumed not to have any influence on productivity. 
We can also calculate the effect on the earnings of unskilled workers (defined as $Y=h E$ ). The reader can verify that this effect is ambiguous (i.e., assumptions about the elasticity of substitution alone are not enough to sign the $d Y / d h$ expression). Work-sharing can thus lead to lower hourly wage inequality but it may also result to higher income inequality.

In any case, what the above findings suggest is that the continued reduction in the hours of work experienced by every OECD country since the start of the $20^{\text {th }}$ century may be a way to explain both the drop in inequality experienced by all countries since the 1920s (see, Gordon (2002)) and its rise in the United States and the United Kingdom since the 1970 s.

\section{Conclusion}

This paper has tried to enquire into the effects of technological change by constructing a model in which both relative demand and relative supply of (un)skilled workers are potentially influenced by it. The model can potentially explain the rise in wage inequality even under the assumption of neutral technological change or even when skill-biased technological change is combined with an elasticity of substitution between skilled and unskilled workers which is lower than one. Moreover, it can partially explain the differences in cross-country patterns of wage inequality as a consequence of diverging developments regarding the size of work-week across the Atlantic. Nevertheless, it shares with many other models the inability to explain both the rise in inequality and the fall in the real wages of the unskilled as well as the cross-country patterns of these variables without relying on further assumptions about the evolution of the relative supplies of (un)skilled workers.

Card and DiNardo (2002) have argued that institutional factors are far more important determinants of the evolution of the wage structure. The drop of the real value of the minimum wage by more than $30 \%$ in 1978 is identified in their study as the institutional development explaining most of the rise in US inequality. Combining this development in the US with the absence of a similar development in continental European countries provides also an empirically plausible explanation for the cross- 
country patterns of wage inequality. Without wishing to question the relevance of the minimum wage explanation, the present paper has also raised the issue of the appropriateness of using rigidly defined categories of factors of production, since these education-based classifications may not correspond to the tasks actually performed by the workers. The implication of this is that the relationship between factor supplies and marginal products may be opposite from what simple-minded applications of the theory of production imply. 


\section{References}

Acemoglu, D., 2002, "Technical Change, Inequality and the Labor Market", Journal of Economic Literature, 40, 1, pp. 7-72.

Autor, D., A. Krueger, and L. Katz, 1998, "Computing Inequality: Have Computers Changed the Labor Market?", Quarterly Journal of Economics, 113, 4, pp. 1169-1213.

Blau, F., and Kahn, L., 2005, "Changes in the Labor Supply of Married Women:19802000”, NBER Working Paper No. 12230.

Berman, E., J. Bound, and S. Machin, 1998, "Implications of Skill Biased Technological Change: International Evidence," Quarterly Journal of Economics 113, 1245-1279.

Blundell, R., and T. MaCurdy, "Labor Supply: A Review of Alternative Approaches," in Orley Ashenfelter and David Card, eds., Handbook of Labor Economics, Volume 3A (Amsterdam: Elsevier, 1999), pp. 1559-1695.

Card, D., and J. DiNardo, 2002, "Skill Biased Technological Change and Rising Wage Inequality: Some Problems and Puzzles", NBER Working Paper No. 8769.

Card, D., F. Kramarz, and T. Lemieux, 1999, "Changes in the Relative Structure of Wages and Employment: A Comparison of the United States, Canada and France", Canadian Journal of Economics, 32, pp. 843-877.

Coleman, M.T. and J. Pencavel, 1993, "Changes in Hours of Work of Male Employee, 19401988”, Industrial and Labor Relations Review, 46,4, pp. 262-283.

Costa, D.L., 1998, "The Wage and the Length of the Work Day: From the 1890s to 1991", NBER Working Paper No. 6504.

Freeman, R., 1995, “Are your Wages Set in Beijing," Journal of Economic Perspectives 9, $15-32$.

Freeman, R. and L. Katz, 1995, "Introduction and Summary", in R. Freeman and L. Katz (eds.), Differences and Change in Wage Structures, University of Chicago Press, Chicago.

Gordon, D., 1995, Fat and Mean:The Corporate Squeeze of Working Americans and the Myth of Managerial "Downsizing”, The Free Press, New York.

Gordon, R., 2002, Discussion of D. Acemoglu, P. Aghion, and G. Violante, “ Technical Change, Deunionization and Inequality", Carnegie-Rochester Conference Series on Public Policy.

Gottschalk, P. and T. M. Smeeding, 1997, "Cross-National Comparisons of Earnings and Income Inequality", Journal of Economic Literature, 35,2, pp. 633-687.

Gregg, P. and A. Manning, 1996, "Skill-Biased Change, Unemployment and Wage Inequality", European Economic Review 41, 1173-1200.

Hamermesh, D.S., 1993, Labor Demand, (Princeton, NJ: Princeton University Press).

Hart, R.A., 1987, Working Time and Employment, Routledge, London. 
Hart, R.A., 2004, The Economics of Overtime Working, Cambridge University Press, Cambridge.

Hart, R.A. and T. Moutos, 1995, Human Capital, Employment and Bargaining, Cambridge University Press, Cambridge.

Hecker, D., 1992, "Reconciling Conflicting Data on Jobs for College Graduates", Montly Labour Review, July, 312.

Juhn, C., K. Murphy, and B. Pierce, 1993, "Wage Inequality and the Rise in Returns to Skill," Journal of Political Economy 101, 410-442.

Krugman, P. 1995, “Technology, Trade and Factor Prices”, NBER Working Paper No. 5355.

Machin, S. and J. Van Reenen, "Technology and Changes in Skill Structure: Evidence from Seven OECD Countries," Quarterly Journal of Economics 113, 1215-1244.

Maddison, A., 1991, Dynamic Forces in Capitalist Development, Oxford University Press, New York.

McCormick, A., L. Horn and P. Knepper, 1996, A Descriptive Summary of 1992/93 Degree Recipients 1 Year Later, US Department of Education, National Center for Education Statistics, Washington, DC.

Mishel, L., J. Bernstein, and J. Smith, 2001, The State of Working America 2000/2001, Cornell University Press, Ithaka, NY.

Moutos, T., 2000, "Neutral Technological Change and the Skill Premium", Economics Letters 69, 365-370.

Murphy, K., C. Riddell and P. Romer, 1998, "Wages, Skills and Technology in the United States and Canada", in E. Helpman (ed.), General Purpose Technologies, The MIT Press, Cambridge Mass.

OECD, 2002, Education at a Glance 2002, Table A41, OECD, Paris.

Nickell, S. and B. Bell, 1996, "The Collapse in the Demand for the Unskilled and Unemployment across the OECD”, Oxford Review of Economic Policy, 11, pp. 40-62.

Wood, A., 1994, North-South Trade, Employment and Inequality, (Oxford: Oxford University Press). 